\title{
Dementia-friendly design of television news broadcasts
}

\author{
Liam Funnell, Isabel Garriock, Ben Shirley and Tracey Williamson
}

\begin{abstract}
Purpose - The purpose of this paper is to understand factors that affect viewing of television news programmes by people living with dementia, and to identify dementia-friendly design principles for television news programmes and factors for personalising object-based media broadcast.

Design/methodology/approach - Extensive public involvement comprising two discussion groups with people with dementia and family carers informed the study design and provided supplementary secondary data. Primary data collection comprised a focus group interview with people with dementia $(n=4)$ and family carers $(n=4)$. Past viewing experiences and perceived barriers and facilitators to viewing television were explored. Participants commented on an array of video clips comprising varying segments of fictional news programmes, plus control versions of each segment.

Findings - Four themes were identified: content (general comments, context, type of media and pace); presenter (body language, clothing and accent); background (location and studio appearance); and technical aspects (graphics, sound, colours, camera, transitions, general issues).

Research limitations/implications - Limitations included a modest sample size which is offset by exemplary public involvement in informing the study design.

Practical implications - Measures ensured research involvement and participation was made accessible to people living with dementia.

Social implications - Participants benefited from sharing views with peers and expressed enhanced wellbeing from knowing their participation could lead to improved television viewing, an important social occupation, for people with dementia in the future.

Originality/value - This study is the first to be published which focusses on dementia-friendly television news programmes.

Keywords Dementia, Television, Design principles, Dementia-friendly design, News programmes

Paper type Research paper

\section{Background}

In 2014, there were 835,000 people in the UK with dementia, and this is projected to increase to over $1 \mathrm{~m}$ people by 2021 (Dowrick and Southern, 2014). According to Hayne and Fleming (2014, p. 1), "Dementia is not a single specific disease, it is an overall term used to describe a syndrome associated with more than 100 different diseases that are characterised by the impairment of brain functions, including language, memory, perception, personality and cognitive skills". Whilst the total financial cost of dementia to the UK has been estimated at £26.3bn (Prince et al., 2014), the human cost is considerable. On a daily basis, people with dementia, even in its earlier stages, may experience major challenges presented by them losing track of conversations (Holst and Hallberg, 2003), losing track of time (Nygård and Borell, 1998), and forgetting names and events (Keady et al., 1995).
\end{abstract}

\section{Introduction}

\section{Television viewing}

There is strong potential for development of programme content that meets the needs and demands of people with cognitive impairments (Knall and Östlund, 2009). A study by Bakker (2003) found that
Liam Funnell, Isabel Garriock and Ben Shirley are all based at School of Computing, Science and Engineering, University of Salford, Salford, UK. Tracey Williamson is based at Salford Institute for Dementia, School of Health and Society, University of Salford, Salford, UK.

Received 11 February 2018

Revised 25 June 2018

7 August 2018

11 August 2018

Accepted 13 August 2018

(C) Liam Funnell, Isabel Garriock, Ben Shirley and Tracey Williamson. Published by Emerald Publishing Limited. This article is published under the Creative Commons Attribution (CC BY 4.0) licence. Anyone may reproduce, distribute, translate and create derivative works of this article (for both commercial and non-commercial purposes), subject to full attribution to the original publication and authors. The full terms of this licence may be seen at http://creativecommons.org/ licences/by/4.0/legalcode 
people living with dementia can sometimes confuse fiction with reality, especially during television viewing. Lund et al. (1995) found that programmes which some viewers with dementia find calming can have the opposite effect on others, causing confusion and distress. Yet the Dementia-friendly Technology Charter (Alzheimer's Society, 2014) identified television as a social activity having potential to enable people to live independently for longer, potentially enhancing the quality of life for both people with dementia and for carers. Therefore, it may be prudent to fine-tune television programmes for people with dementia to best meet their needs. De Medeiros et al. (2009, p. 639) suggest "News programs, game shows, and commercials were identified as the most problematic; comedies, soap operas, and dramas, as moderately problematic; and nature programs, sports, documentaries, and music programs, as least problematic" for people with dementia to watch.

Knall and Östlund (2009) viewed local news programmes as being preferable to national news programmes. Similarly Topo and Östlund (2009) observed that, when watching television, people with dementia in a care facility preferred to watch local news programmes compared to national news. The media that contained people and locations recognised by viewers who had dementia led to higher levels of response. Used correctly, the active use of information and the media can promote healthy ageing (Niemela et al., 2012), whilst a further claim is that people with dementia that live alone could be helped to stave off loneliness (Andrews, 2016) by enhanced connectedness to the outside world through local news and current affairs programmes.

\section{User-friendly television}

People with dementia may struggle with distractions due to a decrease in concentration and a reduced attention span, resulting in stress. Memory problems may also cause them to lose focus whilst watching television as they become lost in the narrative (Andrews, 2016). Family carers may be relied upon to repeat storylines or recap characters for the person with dementia, which may negatively affect their own viewing. Furthermore hearing is often impaired amongst people affected by dementia whose ability to interpret sound accurately reduces, resulting in confusion, illusions, frustration and agitation (Hayne and Fleming, 2014). These sensory challenges may be in addition to those incurred through age-related conditions that further affect sight or hearing (for further information, see www.pocklington-trust.org.uk/treatment-and-diagnosis-2/). These factors can be further compounded by other sensory impairments experienced by people with various forms of dementia (see examples at www. lifechangestrust.org.uk/publications/dementia-sensory-challenges).

Television therefore needs to be user-friendly (Andrews, 2016), both in content and accessing the content. Present-day televisions are often very complex, whilst remote controls used to operate them can have too many buttons that are very small and difficult to read (Logan et al., 1994), with functions that are very rarely used. Various manufacturers have developed easier to handle and use TV remote controls and consumers can find help in selecting what works best to meet their needs from organisations such as Living Made Easy (for more information see www.livingmadeeasy.org. uk/). Biswas (2012) recommended that when designing television applications, user-friendly content should be adapted for people with disabilities or age-related impairments, including large fonts and colour combinations (e.g. white text on a black background).

\section{Broadcasting}

The scheduling of broadcast television programmes allows for the broadcasters to target a particular audience (Armstrong et al., 2014) and there are several access services which can benefit people with sensory impairments, enhancing their viewing. These include closed access services (e.g. sub-titles for hearing impaired people) and audio description (for those with visual impairments) whereby viewers have the option to turn them on or off (Digital Television Group, 2017). Some people with cognitive disabilities find that audio descriptions are useful as it allows them to better understand the programme (Digital Television Group, 2017).

Recent developments in object-based broadcast allow a user to personalise the audio and video content of a television programme to their individual preferences and accessibility requirements (Armstrong et al., 2014). Additional audio and video objects could be broadcast alongside television programmes, which would enhance the experience of users. Whilst the use of additional video objects is currently in the early stages of research, there is a potential for object-based broadcast to 
include additional features such as alternative camera angles, variable levels on specific sound objects and even variable programme length (Armstrong et al., 2014). Shirley and Oldfield (2015) found that there is potential for users to have complete control of the relative levels of all aspects of audio and have demonstrated an object-based audio solution for people who are hard of hearing (Shirley et al., 2017). This would be particularly beneficial in view of hearing losses which are thought to be linked with dementia (Hardy et al., 2016), with one of the main effects of hearing loss being the increased difficulty to separate dialogue surrounded by other background noises in television (Silva, 2016). Whilst our review of available literature has shown that there is currently limited research into what people with dementia struggle with whilst watching television, there is also a lack of research on how requirements could then be addressed.

Previous research has focussed on technological aspects of television viewing such as recognising and manipulating remote controls, sensory impairments or issues relating to agitation of viewers with dementia. What contributes to the originality of the research presented here is its focus on the design of TV news programmes and viewing experiences of those programmes, which we believe to be the first study of its kind. Having considered the needs of people with dementia and the current state of the evidence base for dementia-friendly television, a study focussed on informing dementia-friendly news programme design was carried out.

\section{Study design}

Aims

The purpose of the study was:

- to explore how people with mild to moderate dementia view and consume television programmes on a day-to-day basis;

- to identify barriers and facilitators for people with mild to moderate dementia when watching television;

- to investigate ways in which improvements can be made to current television programmes for people with dementia; and

- to identify design requirements for dementia-friendly television news programmes.

\section{Public involvement approach}

A two-stage approach drawing on best practice principles of public involvement was employed. First, an Advisory Group was formed with help from an experienced dementia researcher. An initial meeting in November 2016 explored advisors' thoughts and feelings of the problems people with dementia experience whilst watching television. Eight volunteers, including five participants with early stage dementia and three family carers from two community dementia support groups, met with the researchers. A facilitated discussion enabled the advisors to explain their experience of the problem under study (Moyle, 2002).

Overall, the group were very enthusiastic about the study as a research priority as they felt television significantly affected each of them either directly, or affected the people they cared for. The discussion also revealed that the most challenging aspects of television viewing related to use of graphics, sound, content and cameras.

At a second meeting, the advisors made suggestions as to the specific design of the planned study and identified topics which they felt were particularly important to explore. As indicated by the literature and as suggested by advisors, this second Advisory Group meeting in January 2017 focussed specifically on aspects of news television programmes as the priority topic to research. The membership had expanded to eleven members. The focussed discussion that followed helped fine-tune the design of the data collection plan.

To gain initial views linked to television news programmes, archive news footage was obtained from both Box of Broadcasts and YouTube. These allowed for a range of clips of varying length to be shown to the group. The clips explored four different sections of news television programmes: "what's 
coming up", studio, weather and news packages. The group were asked to provide constructive criticism on current video clips from news television programmes. The clips shown were recent archive footage from Salford University's student channel Quays News, Quays News Friday First, BBC Newsroom Live, ITV News London, Sky News, Channel 4 News, BBC Sport and BBC World News. The style and content of these clips varied significantly even though they were all news based programmes. This allowed variation in television programmes to be explored. Feedback from both Advisory Group meetings informed subsequent study design and all discussions were filmed.

\section{Ethical approval}

Approval was gained from the University of Salford Research Governance and Ethics Panel. Ethical requirements including risk assessment, written and verbal informed consent to be interviewed and filmed, explanation of right to withdraw and data storage were adhered to.

\section{Theoretical underpinnings}

As the study is unique, several theories have been considered to identify a suitable theoretical framework to underpin it. First, the work of Shakespeare et al. (2017) talked about a social model of disability that differentiated between dementia being seen as an illness or impairment (medical model) and it being a disability (social model) helping to illuminate the exclusion that persons with those impairments may experience. This social model had as its foundations the insights of Oliver (1983), who considered there to be social inequality between people with and without a disability that was evident in interactions between individuals and in behaviours within social institutions, e.g. hospitals and in physical environments. Shakespeare et al. (2017) identified limits of the social model in not acknowledging the complexity of the disability dimension of dementia, and went on to suggest that social relations are as important as the condition itself:

The tendency to over-medicalise dementia, and people with dementia, has obscured the importance

of social conditions that contribute to disabling people with the condition. (Shakespeare et al., 2017)

As the social model was conceived in relation to persons with static physical impairments, it is not as fitting for persons with degenerative conditions such as dementia and a more inclusive approach is proposed (Shakespeare et al., 2017). These authors go on to say how a relational model of disability places more emphasis on people's experiences of living with impairment and illness such as dementia and counters the weakness of the social model at conceptualizing cognitive impairments. A further relevant concept is that of "malignant social psychology (Kitwood, 1997) whereby certain traits and behaviours effect an impact on a person's sense of self. A negative impact will be experienced by persons with dementia where there is a lack of respect and trust from caregivers leading to a state of undermined personhood. The relational model of disability can be considered compounded by malignant social psychology which may result in some persons feeling disrespected and undervalued. Providing television programmes for persons with dementia to watch, which are not tailored to meet their social needs or physical and cognitive abilities, restrict opportunities for inclusion and meaningful occupation and reducing those individuals' sense of worth.

Television programme designers can take steps to make news programme viewing more accessible for people with dementia, and optimise television news viewing as a social activity and as a means of keeping persons' with dementia informed about current affairs. To focus simply on easy-to-use TV remote controls and sub-titles is, in our view, insufficient for making television viewing "dementia enabled" and there is a need to better understand people's experiences of living with dementia in relation to TV viewing.

\section{Methodology and methods}

A qualitative methodology was chosen to elicit detailed understanding of people with dementia's response to media and carer's views of their loved ones experiences with television. A participatory design approach comprising three stages drew on principles of public involvement in research (Hayes et al., 2012). These were: Stage 1, patient and public involvement with lay advisors aimed at exploring the research focus and design; Stage 2, a meeting with lay advisors to explore issues that needed to be investigated and to inform development of news clips for use with fieldwork; and 
Stage 3, data collection comprising a video-recorded group interview with people with dementia and family carers to identify views and preferences concerning mock news clips shown to them. This was complemented by observation of the participants viewing and commenting on sample news clips. Stages 1 and 2 provided secondary data, and Stage 3 provided primary data.

The semi-structured interview guide was developed in light of literature review findings and advice from the study advisors. Interviews sought feedback about each news clip played to participants. As some people with dementia struggle with direct questioning, views were drawn out in a conversational manner using "invitation to respond" (Six Degrees Social Enterprise, 2017), a technique that provides participants the opportunity to join in. A group interview was considered to be more appropriate than individual interviews to encourage group interaction and prompt quieter participants to speak (Kitzinger, 1995).

\section{News clips}

The mock news clips used in Stage 3 were created with media students at the University of Salford's MediaCity UK student TV channel "Quays News" studio. Clips were structured to represent the same four sections of news programme as in the second Advisory Group meeting ("what's coming up", studio, weather and news packages). Each section comprised a "control" clip and other clips providing alternatives with various elements added, changed or removed, based on feedback from the Advisory Group meetings. For the "what's coming up" title, the control sequence contained elements such as animation and graphics. This clip was 30-s long and included cutaways to videos, presenters sitting behind a desk, a music bed and wipe transitions with accompanying "stab" sound. Four alternative versions of the 30-s long "what's coming up" segment were produced: presenters introducing themselves/no wipes; still images instead of videos for the cutaways; presenter simply speaking to camera with no effects added; and a split-screen graphic (presenter on one side and text revealed on the other) with text following the presenter's speech.

\section{Sample and recruitment}

The focus group sample was made up of eight participants $(n=4$ people with dementia, $n=4$ family carers). Most participants were the study advisors who believed it was their right to take part in the study they had co-created. Others were known to the university and regularly took part in research. They also advised that it was better to utilise them as participants as they were oriented to the study rather than start afresh with participants who would struggle to grasp the purpose of the focus group discussion.

Secondary data originated from two Advisory Group meetings of 8 and 11 participants.

\section{Data collection}

Data collection took place in a suite of rooms within The Salford Institute for Dementia. Whilst not a natural environment to watch television in, it was a familiar and comfortable environment for the participants. Once informed consent had been obtained video clips were shown to participants before requesting feedback. Field notes were taken at the time and video footage reviewed following the interview to ensure all participants' views and reactions were included in analyses.

\section{Analysis}

Audio recordings and video footage were transcribed and detailed field notes made during and after the focus group interview. These were reviewed and the transcription coded and grouped into specific themes (Braun and Clarke, 2006) prior to seeking patterns, gaps and aspects in need of further interrogation.

\section{Findings}

The four themes presented here are: Theme 1, content (including general comments, context, type of media and pace); Theme 2, presenter (including body language, clothing and accent); 
Theme 3, background (including location and studio appearance); and Theme 4, technical aspects (including graphics, sound, colours, camera transitions and studio appearance). Themes 1-3 are detailed below in no particular order, whilst Theme 4 is summarised as follows:

Theme 4 - technical aspects affecting news programme viewing:

Graphics:

- simplified title;

- prefer split-screen text graphic (weather as well as map);

- prefer split-screen text to appear simultaneously with speech;

- text needs to match actual wording of presenters;

- font (Neo Pro Tech) considered acceptable;

- name tags preferred large with no animation;

- dislike scrolling text; and

- prefer analogue clock to digital clock.

Sound:

- dislike background noise;

- dislike sound effects;

- music considered unnecessary; and

- prefer more upbeat music to slow music.

Colours:

- prefer brighter colours;

- dislike (yellow) in lower third of screen clashing with (red) studio colour scheme;

- dislike too many colours at once; and

- colours of presenters clothes needs to contrast with studio set background.

Camera:

- dislike camera movement;

- mixed preference on shot of one presenter or of both; and

- prefer closer (head and shoulders) camera shot of presenters.

Transitions:

- dislike wipe transition; and

- dislike pictures displayed in studio before being taken full screen.

General:

- dislike spelling mistakes; and

- news programmes need to be less serious.

\section{Theme 1: content}

\section{General}

Comments were varied but most centred on the idea that the news clip content should be as simple as possible. When shown the simplest variation of the "what's coming up" section, one carer said:

Just plain and simple and what it's all about. 
One carer suggested that the person with dementia they care for would prefer a more upbeat approach. The reason given for this was an anecdote about when musicians perform for dementia support groups and play old-fashioned music which is slow and causes the people with dementia to fall asleep. The carer also mentioned that the same applies to colour and that it should be bright and eye-catching.

\section{Context}

Many comments indicated that it was an essential requirement to give some background details to enable people with dementia to relate new information to prior knowledge. When given the comparison between two alternative versions of a story featuring International Women's Day, the participants agreed that it was better to have a visual reminder of what suffragette Emmeline Pankhurst looked like. One carer said:

That was definitely better because you can see the face of who it's talking about [...] people have memories of who she is then.

When participants were shown alternative versions of a report on "Brexit", the term needed further explanation:

That little bit more information for me is helpful [...] Just a little bit more so I can get my head around, rather than it being just short, sharp. (Person with dementia)

During the weather section, a carer made a suggestion about using a background indicating the season in order to serve as visual reminder of what to expect from the weather forecast. Advice from a carer was to look into using a standardised set of symbols that are easier to see and understand.

When shown a further clip which contained archive footage of Manchester before moving onto modern footage, the response was that it should be more obvious when the transition happens so that there is no confusion about what is old and what is new.

\section{Media}

When including media, such as video clips and photographs, the majority of the participants preferred to have some sort of visual indicator to separate the different segments or to give more context to a news story. One response from a carer was that for a story about a church fire (used in the programme), the point of the story was lost unless pictures of the fire were shown. There was also a suggestion from a participant with dementia that, in this particular case, there should be images of the church before and after the fire because it helps to tell the story.

\section{Pace}

A shared view was that presenters spoke too quickly. It left participants feeling that no sooner had they focussed their attention, the presenters had moved onto the next piece of information.

Changes in images shown were also found to be challenging. For example, in one of the control clips (focussed around International Women's Day), multiple carers and people with dementia commented that the rate at which images appeared was too fast. A carer suggested that it would be better to have one montage containing all six images that could be displayed for longer. A further comment which was made by a carer during a clip featuring a split-screen graphic and descriptive text was that the text needs to be synchronised with the verbal description, otherwise it could be distracting and confusing. In general, using a split-screen graphic was seen as positive, but the participants stressed that it would only work if the text was revealed in time with and identical to the presenter's speech.

\section{Theme 2: the presenter}

\section{Body language}

There were many comments from people with dementia, and from carers, who found the way the presenters moved their arms distracting. One frequently raised issue was that presenters were 
viewed as sitting too rigidly. A participant who has dementia described them as "clinical" and "a bit cardboard". However, there was a clarification that they did not want the presenters to be too relaxed either. One participant with dementia detailed that they would like it if, when one presenter was talking, the other one could turn and look at them because it would look more relaxed and also help to show where attention should be focussed.

\section{Clothing}

The participants made remarks about the clothes worn by the presenters on multiple occasions. They generally found the most faults with the female presenter's outfit, which consisted of a coral coloured blazer on top of a shirt with birds printed on it. The participants felt that the colour was too close to the mostly red studio background and one person said that the presenter seemed to merge into the background.

\section{Accent}

During the Advisory Group meetings, advisors had stated that they liked clear, not broad local accents. In the clips, one of the presenters had a clear accent whereas the other presenter had a strong Irish accent. The overwhelming general response was that accents should be as clear as possible and ideally not too "local" or strong.

\section{Theme 3: background}

\section{Location}

Generally, it was thought by most participants that filming of the weather section should be done as locally as possible, however, one person with dementia said that they became distracted and were unable to pay attention because they were too busy trying to recognise the buildings and the locality. When asked if they would prefer the weather section to be filmed outside or in a studio, the consensus was that it was better done outside. However, one clip of ripples on an open expanse of water was a distraction as they found it confusing and eye-catching.

\section{Studio appearance}

When it came to the appearance of the studio, the set and lighting were the two major components that stood out to participants. The first was the shiny reflective desk and the second was movement on the projected display behind the presenters as it was considered too distracting.

\section{Theme 4: technical aspects}

The list "Theme 4 - technical aspects affecting news programme viewing" summarises key technical aspects affecting viewing.

\section{Discussion}

These findings clearly suggest that there are distinct features of television news programmes which can be made more dementia-friendly. The study identified programme design features around content and delivery which significantly affected participants' ability to comprehend meaning and follow a story. Other aspects were distracting from what was being shown or said and similarly limited comprehension. Factors included content, its ordering and pace of delivery along with the location of filming and studio appearance. Presenters' appearance, clothing, accents and mannerisms were also key issues which could facilitate or distract good quality viewing for people with dementia. Technical aspects included unhelpful use of graphics, unnecessary camera movement, inappropriate use of music and background sound, and use of dull colours and jerky transitions. 
The findings we present have illuminated how some people with dementia consume television programmes on a day-to-day basis and barriers to viewing television. A common barrier was the need to reduce distraction through keeping presentation as simple as possible; this links with the research carried out by Andrews (2016) that states that distractions can result in stress. This factor extended to the presenters' appearance, the studio, the location of reports, e.g. weather bulletin being filmed outdoors, and graphics used. Key elements such as the speed of transitions and presenters' speech, body language and use of variable symbols during weather reports, further hampered viewing. Background noise, from the environment, music or sound effects, was not found to add anything positive to the viewing experience.

Another barrier was the challenge presented by a lack of context within the news items, whether delivered through speech or media such as photographs. Within the Parliament themed control clip, one participant complained that they were unable to understand the information due to not knowing what a term meant (Brexit). This was also prevalent in the International Women's Day clip when the participants preferred to be shown a photo of one of the key figures in the story. A further hindrance was the difficulty in differentiating between historical information and present-day information, due to timeframes not being indicated.

The findings of our study also identify improvements that can be made to make television programmes more accessible for people with dementia, with particular emphasis on requirements for dementia-friendly news programmes. Additional techniques beyond reducing distractions were identified as necessary to enhance viewing including the use of bright colours, keeping discussions upbeat and improving presenter interaction. Our evidence suggests these techniques could facilitate focus and engagement with the programmes, due to their being attractive, attention grabbing and, in terms of presenter interaction, natural and therefore easier to follow. Backgrounds can help understanding when they are commensurate with the content of what is being presented yet too much activity or movement in any background can be distracting. There is a balance to be made between maintaining interest and reducing distractions.

Context is similarly an aspect that can be addressed to maximise the viewing experience of people with dementia. Making sure that the information is presented visually, in an appropriate order and supplemented by text and speech is helpful in setting the scene and leading the viewer through a story. Speech and text need to be simultaneous and not too rapid, with text that is identical to what is being spoken. Clear differentiation between old and new footage would be advantageous and it may also help to prevent the family members' own television viewing experiencing being impacted as described by Haynes and Fleming (2014).

A further aid to comprehension is to allow time for people with dementia to process information. An example of how this can be achieved is by using images to illustrate and separate news stories or sections, enabling the viewer to pause and assimilate information. Clear delivery through presenters not having a broad accent was also found to be beneficial.

Our study uncovered that when designing a dementia-friendly television news programme, viewers may benefit from having the programme presented in a specific format that reflects that which they may have become accustomed to over their lifetime. Therefore, in order to keep a programme easily recognisable as "the news", it was found to be necessary for elements such as the presenter's clothing to be formal and smart. Furthermore, it would be prudent to ensure that the colour of individual presenter's clothing does not clash or merge in with the background as well as careful use of graphics. Over 100 types of dementia are known to exist and some of these have particular association with impaired vision such a Lewy Body Dementia (Royal National Institute for Blind People, 2018).

Our findings indicate a few simple steps which, if adopted by news programme producers, could enable them to create television news programmes which are more accessible to people with dementia. Furthermore, a range of steps can be taken to make programmes optimally dementia-friendly, which we suggest should not affect production costs unduly. Some of these steps will require changes to presenter's styles of presentation and they may have training 
needs which need meeting to equip them for this. Training may also benefit staff involved in television production to help them better understand the needs of people with dementia, that they may then create bespoke programmes, or at least reduce the inaccessibility of programmes generally.

Some aspects identified in this study, such as presenter appearance and delivery style, would require alteration to broadcast media production to make it more acceptable to people with dementia. Others may be open to personalisation based on viewer requirements using forthcoming object-based media formats. Background pictures, graphics and on-screen text and logos are all elements that were identified as problematic, and are all items that could be broadcast as media objects in an object-based media broadcast. BBC research has developed example personalisation for weather graphics that could be personalised by the viewer (Leonard, 2015), radio that can adapt the level of content detail based on listener preferences (BBC, 2015), and have proposed tools and workflows for scalable object-based media production (Cox et al., 2017). It seems likely that such methods could be used to personalise broadcast media for people with dementia, particularly in the case of augmented elements such as graphics and on-screen text.

The issues discussed here are relevant to people without dementia who view television news programmes; however, we found that for people with dementia, the challenges are amplified. It is therefore important to consider carefully, how to prevent people with dementia from becoming distracted whilst also maintaining their focus and attention.

Limitations of the study pertain to the modest sample size which included people who were in the relatively early stages of dementia and family carers speaking on behalf of people with more advanced dementia. The approach to sampling was in response to patient and public involvement good practice and the advice given by study lay advisors with experience of dementia. New methodological insights have been made possible by advisors' recommendation that they comprised most of the participant sample. They believed their prior orientation to the study design was critical to successful participation. Another insight was that participants did not realise how much they did not like something until they were given the option to see a clip without it; hence, the use of control clips and variations on the same clip proved to be an effective approach to determining participant views.

The key strength of this study is that it provides valuable insights into a subject area about which no substantive research has been found. Second, it is a good example of public involvement in research amongst an "easy to ignore" population who are often excluded from research (Taylor et al., 2012). The results provide the basis for future development of best practice guidance for programme creators developing dementia-friendly television news programmes. The evidence we have developed may also be used in facilitating media personalisation for people with dementia.

\section{Conclusions}

Overall, many of the factors that constitute dementia-friendly television are related, such as capturing attention and preventing distraction. This research has indicated the production elements that limit people with dementia from successfully comprehending television news programmes including extras which distract from the key points, not enough stimulation to maintain attention, lack of sufficient context in photos and speech, not making changes obvious enough which can create confusion, not maintaining the expected format of the news and not taking into account age-related conditions that many people with dementia may also have. This study has evaluated how people in the early stages of dementia view and consume media and explored the reactions of people with dementia when viewing a standard television news programme in comparison to altered versions. It has also identified ways in which improvements can be made to current television news programmes in order to help make them more accessible to people with dementia (see Guidance for developing dementia-friendly television (news broadcasts)). In summary, the production and technical elements of a television news programme for people with dementia need to be as simple as possible, whilst still containing enough factors to hold their attention. Object-based media is identified as having 
the potential to provide personalised broadcast that could facilitate improvement in some of the areas identified.

Guidance for developing dementia-friendly television (news broadcasts).

Dementia-friendly television requirements are as follows:

- no background noise (unless necessary to the news item) or sound effects to be used;

- simplified titles without the use of fast moving images;

- split screen in the "what's coming up" section with the text appearing as it is spoken as well as directly matching the presenter;

- the weather presented in a split-screen format with weather symbols only for that day;

- use of an analogue clock displaying the time as well as the day of the week;

- bright and cheerful colour scheme with colours that do not clash or introduce too many different colours at once;

- tight-framed camera shots of only the presenter's head and shoulders;

- no camera movement;

- no use of wipe transitions; and

- light-hearted and not too heavy-going.

\section{Recommendations and future research}

Future research is needed to replicate this study design with larger numbers of participants, especially those with dementia, carefully separating out the views of carers to identify the most important factors in need of addressing by television producers. Future enquiry could focus on the variation of individual design components, e.g. nature of transitions (preferred speed, frequency, design, etc.) and music that is acceptable (type of music, loudness, duration, etc.). Further research could produce object-based broadcasts which will allow a user to customise the audio and video content of a television programme to their individual preferences and accessibility requirements, rather than aiming to achieve "a one size fits all" approach.

\section{References}

Alzheimer's Society (2014), Dementia-Friendly Technology Charter, Alzheimer's Society, London.

Andrews, J. (2016), "Telly On" - Older People, Dementia and the Potential of Television, Dementia Services Development Centre, Stirling, available at: http://juneandrews.net/perch/resources/tellyonfinalpdf.pdf (accessed 8 February 2018).

Armstrong, M., Brooks, M., Churnside, A., Melchior, M. and Shotton, M. (2014), "Object-based broadcasting-curation, responsiveness and user experience", The International Broadcasting Convention Proceedings of the IBC, Amsterdam, pp. 1-8.

Bakker, R. (2003), "Sensory loss, dementia, and environments", Generations, Vol. 27 No. 1, pp. 46-51.

BBC (2015), "Responsive Radio. BBC Taster", available at: www.bbc.co.uk/taster/pilots/responsive-radio (accessed 8 February 2018).

Biswas, P. (2012), "An inclusive approach to develop web TV applications", Journal of Assistive Technologies, Vol. 6 No. 3, pp. 221-5.

Braun, V. and Clarke, V. (2006), "Using thematic analysis in psychology", Qualitative Research in Psychology, Vol. 3, pp. 77-101.

Cox, J., Brooks, M., Forrester, I., Armstrong, M. and Stenton, P. (2017), "Moving object-based media production from one-off examples to scalable workflows", The International Broadcasting Convention Proceedings of the IBC, Amsterdam, pp. 1-8. 
De Medeiros, K., Beall, E., Vozzella, S. and Brandt, J. (2009), "Television viewing and people with dementia living in long-term care: a pilot study”, Journal of Applied Gerontology, Vol. 28 No. 5, pp. 638-48.

Digital Television Group (2017), "R-Book 7 quick guide”, available at: http://dtg.org.uk/dtg/accessibility.html? tab=services (accessed 8 February 2018).

Dowrick, A. and Southern, A. (2014), Dementia 2014: Opportunity for Change, Alzheimer's Society, London.

Hardy, C.J., Marshall, C.R., Golden, H.L., Clark, C.N., Mummery, C.J., Griffiths, T.D., Bamiou, D.E. and Warren, J.D. (2016), "Hearing and dementia", Journal of Neurology, Vol. 263 No. 11, pp. 2339-54.

Hayes, H., Buckland, S. and Tarpey, M. (2012), Briefing Notes for Researchers: Public Involvement in NHS, Public Health and Social Care Research, INVOLVE, Eastleigh.

Hayne, M.J. and Fleming, R. (2014), "Acoustic design guidelines for dementia care facilities", paper presented at Inter.noise 43rd International Congress on Noise Control Engineering, Melbourne.

Holst, G. and Hallberg, I.R. (2003), "Exploring the meaning of everyday life, for those suffering from dementia”, American Journal of Alzheimer's Disease and other Dementias, Vol. 18 No. 6, pp. 359-65.

Keady, J., Nolan, M. and Gilliard, J. (1995), "Listen to the voices of experience", Journal of Dementia Care, Vol. 3 No. 3, pp. 15-17.

Kitwood, T. (1997), Dementia Reconsidered: The Person Comes First, Open University Press, Buckingham.

Kitzinger, J. (1995), "Qualitative research: introducing focus groups", BMJ: British Medical Journal, Vol. 311 No. 7000, pp. 299-302.

Knall, G. and Östlund, B. (2009), "People with dementia watch television! But why?", Assistive Technology Research Series, Vol. 24, pp. 29-43.

Leonard, M. (2015), "Forecaster: our experimental object-based weather forecast”, RandD Blog, available at: www.bbc.co.uk/rd/blog/2015-11-forecaster-our-experimental-object-based-weather-forecast (accessed 14 December 2017).

Logan, R., Augaitis, S. and Renk, T. (1994), "Design of simplified television remote controls: a case for behavioral and emotional usability", Proceedings of The Human Factors and Ergonomics Society Annual Meeting in Nashville, Sage Journals, Vol. 38, London, No. 5, pp. 365-9.

Lund, D., Hill, R., Caserta, M. and Wright, S. (1995), "Video respite: an innovative resource for family, professional caregivers, and persons with dementia", The Gerontologist, Vol. 35 No. 5, pp. 683-7.

Moyle, W. (2002), "Unstructured interviews: challenges when participants have a major depressive illness", Journal of Advanced Nursing, Vol. 39 No. 3, pp. 267-73.

Niemelä, R., Huotari, M. and Kortelainen, T. (2012), "Enactment and use of information and the media among older adults”, Library and Information Science Research, Vol. 34 No. 3, pp. 212-19.

Nygård, L. and Borell, L. (1998), "A life-world of altering meaning: expressions of the illness experience of dementia in everyday life over 3 years", OTJR: Occupation, Participation and Health, Vol. 18 No. 2, pp. 109-36.

Oliver, M. (1983), Social Work with Disabled People, Palgrave Macmillan, Basingstoke.

Prince, M., Knapp, M., Guerchet, M., McCrone, P., Prina, M., Comas-Herrera, A., Wittenberg, R., Adelaja, B., Hu, B., King, D., Rehill, A. and Salimkumar, D. (2014), Dementia UK: Second Edition - Overview, Alzheimer's Society, London.

Royal National Institute for Blind People (2018), "Dementia and sight loss”, available at: www.rnib.org.uk/ sites/default/files/Sight\%20loss\%20and\%20dementia\%20leaflet.pdf (accessed 22 June 2018).

Shakespeare, T., Zeilig, H. and Mittler, P. (2017), "Rights in mind: thinking differently about dementia and disability”, Dementia, available at: https://doi.org/10.1177/1471301217701506 (accessed 31 June 2019).

Shirley, B. and Oldfield, R. (2015), "Clean audio for TV broadcast: an object-based approach for hearingimpaired viewers", Journal of the Audio Engineering Society, Vol. 63 No. 4, pp. 245-56.

Shirley, B.G., Meadows, M., Malak, F., Woodcock, J.S. and Tidball, A. (2017), "Personalized object-based audio for hearing impaired TV viewers", Journal of the Audio Engineering Society, Vol. 65 No. 4, pp. 293-303. 
Silva, S. (2016), "Object-based audio for sports TV production", SMPTE Motion Imaging Journal, Vol. 125 No. 9, pp. 1-5.

Six Degrees Social Enterprise (2017), "Empowered conversations: communication training for carers of people living with dementia”, available at: http://empowered-conversations.co.uk/ (accessed 9 February 2018).

Taylor, J.S., DeMers, S.M., Vik, S. and Borson, S. (2012), "The disappearing subject: exclusion of people with cognitive impairment and dementia from geriatrics research", Journal of Amercian Geriatrics Society, Vol. 60 No. 3, pp. 413-19.

Topo, P. and Östlund, B. (Eds) (2009), "Dementia, design and technology: time to get involved", Assistive Technology Research Series, Vol. 24, IOS Press, Amsterdam, pp. 36-7.

\section{Further reading}

McGettrick, G. and Williamson, T. (2015), Dementia, Rights and the Social Model of Disability, Mental Health Foundation, London.

Simonson, W. (2014), "When will there be a cure for dementia?", Geriatric Nursing, Vol. 35 No. 3, pp. 225-6.

\section{Corresponding author}

Tracey Williamson can be contacted at: t.williamson@worc.ac.uk

For instructions on how to order reprints of this article, please visit our website:

www.emeraldgrouppublishing.com/licensing/reprints.htm

Or contact us for further details: permissions@emeraldinsight.com 